\title{
Estimating net primary productivity from grassland biomass dynamics measurements
}

\author{
J. M. O. SCURLOCK, K. JOHNSON and R. J. OLSON \\ Environmental Sciences Division, Oak Ridge National Laboratory, PO Box 2008, Oak Ridge, TN 37831-6407, USA
}

\begin{abstract}
To address the need for a high quality data set based upon field observations suitable for parameterization, calibration, and validation of terrestrial biosphere models, we have developed a comprehensive global database on net primary productivity (NPP). We have compiled field measurements of biomass and associated environmental data for multiple study sites in major grassland types worldwide. Where sufficient data were available, we compared aboveground and total NPP estimated by six computational methods (algorithms) for 31 grassland sites. As has been found previously, NPP estimates were 2-5 times higher using methods which accounted for the dynamics of dead matter, compared with what is still the most commonly applied estimate of NPP (maximum peak live biomass). It is suggested that assumptions such as the use of peak biomass as an indicator of NPP in grasslands may apply only within certain subbiomes, e.g. temperate steppe grasslands. Additional data on belowground dynamics, or other reliable estimates of belowground productivity, are required if grasslands are to be fully appreciated for their role in the global carbon cycle.

Keywords: aboveground, belowground, carbon cycle, data, grasslands, net primary productivity

Received 8 May 2001; revised version received 9 January 2002 and accepted 19 February 2002
\end{abstract}

\section{Introduction}

Net primary productivity (NPP) is an important component of the global carbon cycle, yet progress in developing predictive terrestrial biosphere models has been inhibited by the lack of a high quality dataset based upon field observations (Cramer et al., 1996; Scurlock et al., 1999). In the context of advancing global change science, data on terrestrial NPP are more widely available than other estimates of biosphere-atmosphere exchange of carbon such as Gross Primary Productivity (GPP) and Net Ecosystem Exchange/Net Ecosystem Production (NEE/ NEP). NPP data provide one approach to an improved understanding of ecosystem dynamics, although other factors, such as heterotrophic respiration through herbivory and decomposition, determine the net biospheric exchange of carbon. In a recent synthesis of flux studies, Buchmann \& Schulze (1999) noted 'different levels of organization' of gas exchange, whereby 'NPP represents

Correspondence: Dr R. J. Olson, Environmental Sciences Division, Bldg. 1507/MS-6407, Oak Ridge National Laboratory, PO Box 2008, Oak Ridge, TN 37831-6407, USA,

e-mail: olsonrj@ornl.gov the stand level (vegetation only), and NEP represents the ecosystem level (including soils)'. Over the past 5-10 years, a number of international global change model intercomparison meetings, as well as analyses of terrestrial carbon sinks, have shown the need for additional data to constrain models. NPP is a common variable utilized by many different models, providing a 'benchmark' which enables cross-comparisons (Hibbard \& Sahagian, 1998; Cramer et al., 1999; Olson et al., 2001). However, problems remain with synthesizing and modelling inconsistency in measurement techniques between NPP studies separated in space and time (Scurlock \& Olson, 2001).

To address the absence of a consistent field data set, we have developed a global database of estimates of terrestrial NPP, derived from the literature on ecophysiological field work and from interaction with the scientific community. This uniquely large and comprehensive archive of NPP and biomass dynamics data is now available through the Oak Ridge National Laboratory (ORNL) Distributed Active Archive Centre (DAAC), and may be especially useful for model and hypothesis testing (Jager et al., 2000; Scurlock \& Olson, 2001; www.daac.ornl.gov / NPP/). The data on grasslands include biomass dynamics and associated environmental data for over 


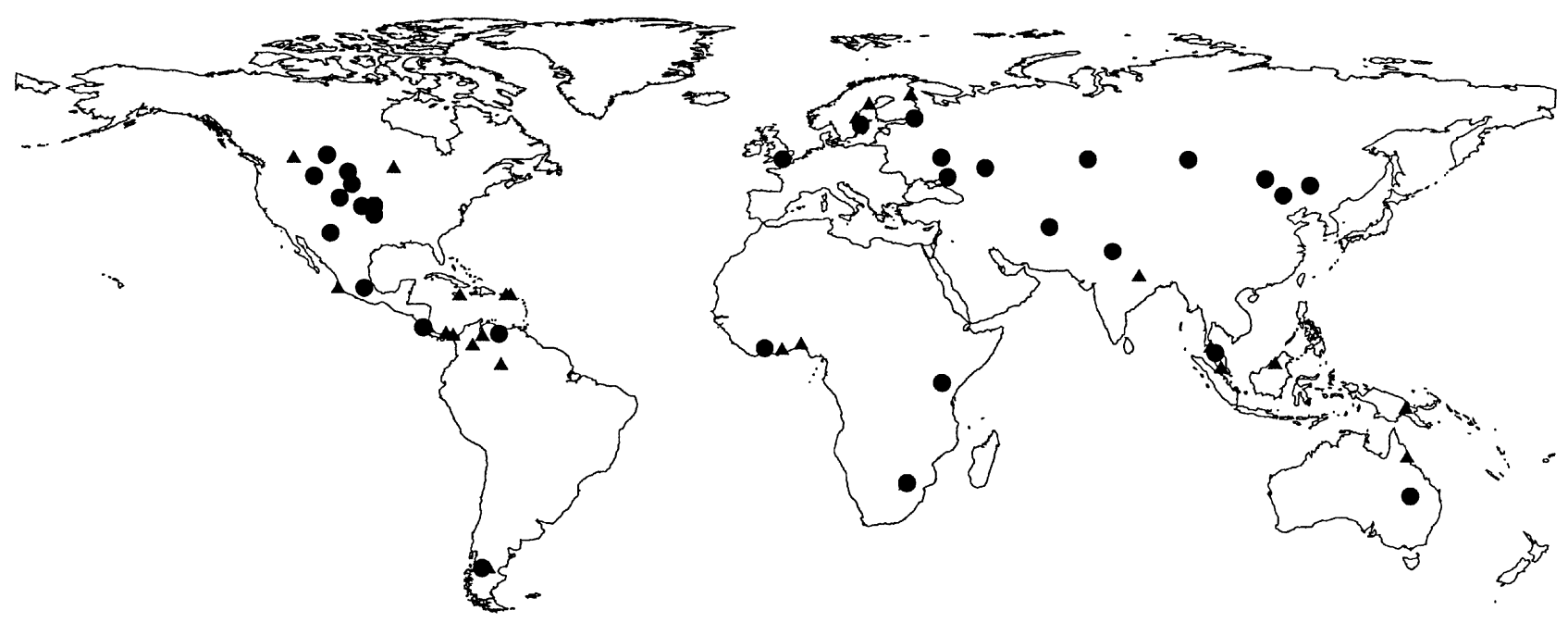

Fig. 1 Map showing the geographical distribution of detailed terrestrial NPP study sites in the Oak Ridge National Laboratory (ORNL), Distributed Active Archive Center database. $\bullet=31$ grassland sites included in the present analysis; $\boldsymbol{\Delta}=$ grassland sites for which suitable data were not available, and NPP study sites in other biomes (tropical forest, boreal forest). These data, and further information about the study sites, are publicly available at www.daac.ornl.gov/NPP/.

35 study sites, of which 31 have sufficient data on biomass dynamics to carry out the analysis reported here. Together, these study sites represent a broad range of grassland types, as defined by ecoregions (Bailey, 1989) or climatic zones (Fig. 1; Table 1).

In this paper we re-examine the issue of NPP estimation in grasslands, described below, in the light of a larger number and wider range of data sets available online.

\section{Grassland NPP estimation}

NPP is defined as the total photosynthetic gain, less respiratory losses, of vegetation per unit ground area. For natural vegetation, this is often expressed on an annual basis. For a given period of measurement, NPP is equal to the change in both aboveground and belowground plant mass plus any losses over this period due to death and subsequent decomposition, herbivory and exudation/volatilization (Long et al., 1989, 1992; Roberts et al., 1993). However, many earlier estimates of grassland NPP ignored both turnover and belowground production, and were based on aboveground peak 'standing crop' only (i.e. total clipped live and dead matter, e.g. Kucera et al., 1967). Even the coordinated studies of the International Biological Programme (IBP) Grassland Biome in the late 1960s and early 1970s were based mainly on aboveground biomass changes, with relatively few estimates of belowground productivity (Singh \& Joshi, 1979; Long et al., 1989).

Singh et al. (1975) and Long et al. (1989) reviewed and discussed the limitations of the various methodologies for estimating NPP of grasslands and similar ecosystems.
These methods can be grouped under the seven NPP estimation algorithms outlined in Table 2. Peak aboveground live biomass (Method 1), peak [aboveground live plus dead matter] (Method 2), or the difference between maximum and minimum biomass (Method 3) have been, and are still, commonly used as an estimate of NPP usually where only one or two measurements per year are available. Sometimes conversion factors have been applied to estimate turnover, successive peaks of different codominant species, or the ratio of belowground to aboveground production (Singh et al., 1975). The 'IBP Standard Method' of Milner \& Hughes (1968) assumed that where grassland live biomass increased between successive samples, production equalled this increase; where biomass decreased or remained the same, production was assumed to be zero. Annual productivity was then obtained by summing the estimates for each sample interval (Method 4). Essentially, this method was used for the IBP Grassland Biome synthesis of Singh \& Joshi (1979), in particular for their estimates of belowground NPP. However, a modification of the IBP Standard Method was also evaluated for aboveground production (Singh \& Yadava, 1974; Singh et al., 1975). Where increases in standing dead matter coincided with increments in live biomass, they were added to the monthly production, and where only the sum of live and standing dead showed an increase, this was counted as monthly production (Methods 5 and 6). This NPP algorithm is computationally more complex since a decision matrix is needed to determine whether or not individual increments contribute towards annual NPP, and is sometimes referred to as 'Smalley's method' (Linthurst \& Reimold, 
Table 1 Characteristics of 31 grassland study sites used in the present analysis, and principal reference for each study, grouped by ecoregion. Abbreviated three-letter site codes, based upon the name of each study site, were used to distinguish between the study sites and to label the data files associated with each one. Rainfall, Temperature = mean annual rainfall and temperature for nearest weather station, as reported in the original literature; $\mathrm{C} 3 / \mathrm{C} 4=$ dominant photosynthetic type of dominant species (C4 grasses generally have higher water use and nitrogen use efficiency); Ecoregion = classification after Bailey (1989); N/A = not available

\begin{tabular}{|c|c|c|c|c|c|c|c|c|}
\hline $\begin{array}{l}\text { Site } \\
\text { code }\end{array}$ & Name & Country & $\begin{array}{l}\text { Rainfall } \\
(\mathrm{mm})\end{array}$ & $\begin{array}{l}\text { Temperature } \\
\text { (C) }\end{array}$ & $\begin{array}{l}\text { Elevation } \\
(\mathrm{m})\end{array}$ & $\mathrm{C} 3 / \mathrm{C} 4$ & Ecoregion & Reference \\
\hline brd & Bridger & USA & 395 & 2.7 & 2340 & $\mathrm{C} 3$ & Cold steppe & Sims et al. (1978) \\
\hline $\operatorname{shr}$ & Shortandy & Kazakhstan & 350 & 1.3 & 367 & $\mathrm{C} 3$ & Cold steppe & Gilmanov et al. (1997) \\
\hline $\operatorname{tmg}$ & Tumugi & China & 411 & 2.1 & 191 & $\mathrm{C} 3$ & Cold steppe & Xiao et al. (1996b) \\
\hline $\operatorname{tmn}$ & Tumentsogt & Mongolia & 269 & 1.7 & 1100 & $\mathrm{C} 3$ & Cold steppe & Togtohyn et al. (1996) \\
\hline tva & Tuva & Russia & 285 & -4.3 & 800 & $\mathrm{C} 3$ & Cold steppe & Gilmanov et al. (1997) \\
\hline$x \ln$ & Xilingol & China & 361 & -2.0 & 1200 & $\mathrm{C} 3$ & Cold steppe & Xiao et al. (1996a) \\
\hline bdk & Badkhyz & Turkmenistan & 310 & 12.6 & 700 & C3 & Temperate dry steppe & Gilmanov et al. (1997) \\
\hline cpr & CPER/SGS & USA & 334 & 9.9 & 1625 & $\mathrm{C} 4$ & Temperate dry steppe & Lauenroth \& Sala (1992) \\
\hline $\mathrm{ctt}$ & Cottonwood & USA & 400 & $\mathrm{~N} / \mathrm{A}$ & 744 & C3 & Temperate dry steppe & Sims et al. (1978) \\
\hline dck & Dickinson & USA & 425 & 4.8 & 784 & $\mathrm{C} 3$ & Temperate dry steppe & Sims et al. (1978) \\
\hline $\mathrm{dzh}$ & Dhzanybek & Kazakhstan & 291 & 5.0 & 20 & $\mathrm{C} 3$ & Temperate steppe & Gilmanov et al. (1997) \\
\hline hys & Hays & USA & 564 & 12.2 & 714 & $\mathrm{C} 4$ & Temperate steppe & Sims et al. (1978) \\
\hline mdl & Media Luna & Argentina & 338 & 5.5 & 630 & C3 & Temperate steppe & Defosse et al. (1990) \\
\hline mtd & Matador & Canada & 350 & 3.0 & 676 & $\mathrm{C} 3$ & Temperate steppe & Coupland (1973) \\
\hline $\mathrm{clb}$ & Calabozo & Venezuela & 1252 & 28.3 & 98 & $\mathrm{C} 4$ & Humid savanna & San Jose \& Medina (1976) \\
\hline cns & Cañas & Costa Rica & 1926 & 28.0 & 45 & $\mathrm{C} 4$ & Humid savanna & Daubenmire (1972) \\
\hline$k \ln$ & $\begin{array}{l}\text { Klong Hoi } \\
\text { Khong }\end{array}$ & Thailand & 1541 & 26.4 & 30 & $\mathrm{C} 4$ & Humid savanna & $\begin{array}{l}\text { Kamnalrut \& Evenson } \\
\text { (1992) }\end{array}$ \\
\hline krk & Kurukshetra & India & 688 & 23.6 & 247 & $\mathrm{C} 4$ & Humid savanna & Singh \& Yadava (1974) \\
\hline $\operatorname{lmt}$ & Lamto & Cote d'Ivoire & 1165 & 28.8 & 300 & $\mathrm{C} 4$ & Humid savanna & Menaut \& Cesar (1979) \\
\hline mnt & Montecillo & Mexico & 580 & 14.2 & 2240 & $\mathrm{C} 4$ & Humid savanna & $\begin{array}{l}\text { Garcia-Moya \& Montanez } \\
\text { Castro (1992) }\end{array}$ \\
\hline ben & Beacon Hill & UK & 858 & 11.0 & 205 & $\mathrm{C} 3$ & Humid temperate & Williamson (1976) \\
\hline $\mathrm{khm}$ & Khomutov & Ukraine & 424 & 11.1 & 75 & $\mathrm{C} 3$ & Humid temperate & Gilmanov et al. (1997) \\
\hline $\mathrm{knz}$ & Konza & USA & 859 & 12.6 & 400 & $\mathrm{C} 4$ & Humid temperate & Abrams et al. (1986) \\
\hline krs & Kursk & Russia & 594 & 6.1 & 250 & $\mathrm{C} 3$ & Humid temperate & Gilmanov et al. (1997) \\
\hline osg & Osage & USA & 1014 & 15.2 & 392 & $\mathrm{C} 4$ & Humid temperate & Sims et al. (1978) \\
\hline otr & Otradnoe & Russia & 485 & 8.6 & 50 & $\mathrm{C} 3$ & Humid temperate & Gilmanov et al. (1997) \\
\hline tll & Tullgarnsnaset & Sweden & 528 & 2.5 & 0 & $\mathrm{C} 3$ & Humid temperate & Wallentinus et al. 1973) \\
\hline chr & Charleville & Australia & 457 & 19.4 & 304 & $\mathrm{C} 3$ & Savanna & Christie (1978) \\
\hline jrn & Jornada & USA & 276 & 14.9 & 1350 & $\mathrm{C} 4$ & Savanna & Sims et al. (1978) \\
\hline nls & Nylsvley & South Africa & 666 & 17.1 & 1100 & $\mathrm{C} 4$ & Savanna & Scholes \& Walker (1993) \\
\hline nrb & Nairobi & Kenya & 677 & 19.7 & 1600 & $\mathrm{C} 4$ & Savanna & $\begin{array}{l}\text { Kinyamario \& } \\
\text { Imbamba (1992) }\end{array}$ \\
\hline
\end{tabular}

1978; Roberts et al., 1993) or 'trough-peak' analysis of live plus dead matter (Singh et al., 1975). This method also needs to state explicitly whether only recent (standing) dead matter increments are to be considered (Singh et al., 1975; Method 5), or changes to total dead matter, including litter (Linthurst \& Reimold, 1978; Method 6).

The peak biomass method and variations on the IBP method underestimate productivity by not accounting for simultaneous growth and death (Long et al., 1989). Whilst this may not be significant in ecosystems with short growing seasons and near-complete mortality inbetween, it may occur in temperate grasslands with a long growing season, and is particularly a problem in tropical grasslands where the growing period may extend over much of the year. Underestimation of fine root turnover (and hence NPP) is probably the largest source of error (Long et al., 1989), although some degree of overestimation may occur by not accounting for periods of negative NPP (due to stress, or translocation between above- and belowground plant parts), or by summing changes in biomass which are not statistically significant (Singh et al., 1975; Biondini et al., 1991). Perhaps the most elaborate method of determining NPP is that of Long and coworkers, who estimated NPP by summing monthly changes in live biomass plus losses due to death and decomposition, for both aboveground 
Table 2 NPP estimation algorithms used in the present study, their characteristics, and the names of variables used for SAS ${ }^{\mathrm{TM}}$. coding (see footnote)

\begin{tabular}{llll}
\hline Method & Description & Calculation & Reference \\
\hline 1. & Peak live biomass & MAX (AGbmass) & Singh et al. (1975); Long et al. (1989)
\end{tabular}

Assumptions: any standing dead matter or litter was carried over from previous year, and death in current year is negligible; live biomass was not carried over from previous year; belowground production is ignored, or estimated only as a fraction of aboveground production using a crude root/shoot ratio

Conclusions: may be applicable to annual arable crops, but clearly a poor estimate of production for perennial vegetation (i.e. most natural plant communities), especially where belowground turnover may be significant. May be useful for crude comparisons between seasonal temperate grasslands, but has little meaning for tropical grasslands, and should definitely not be used to compare temperate and tropical grasslands

2. Peak standing crop

(live plus standing dead matter)

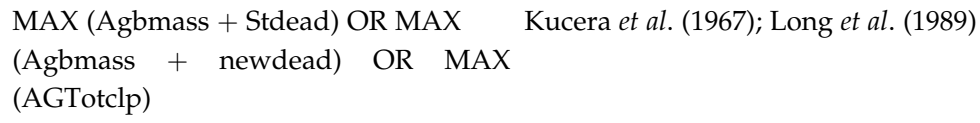

Assumptions: any standing dead matter was formed by death in current year, hence counts as part of this year's plant production; no standing dead matter has yet fallen as litter or decomposed; neither live biomass nor standing dead matter were carried over from previous year; belowground production is ignored, or estimated only as a fraction of aboveground production using a crude root/shoot ratio

Conclusions: same as for Method 1 above; may be a slightly better estimate of NPP where significant death occurs during the growing season

3. Maximum minus minimum live biomass

$$
\text { MAX (Agbmass) - MIN (Agbmass) Singh et al. (1975); Long et al. (1989) }
$$

Assumptions: same as for Method 1, but any live biomass carried over from the previous year is excluded

Conclusions: same as for Method 1 above; subtraction of minimum biomass is likely to be a useful correction only under limited conditions

4. Sum of positive increments

SUM (positive increments in Agbmass) Milner \& Hughes (1968)

in live biomass

Assumptions: most growth occurs between successive sample intervals, i.e. simultaneous growth and death do not occur; NPP is never negative during a sample interval; belowground production may be similarly measured, ignored altogether, or estimated only as a fraction of aboveground production using a crude root/shoot ratio

Conclusions: allows for several distinct phases of growth within a year, but still fails to account for new shoot growth during periods of high mortality, and vice versa. However, for sites where data on biomass dynamics are available (preferably both above- and belowground) a more dynamic comparison of NPP may be possible. Nevertheless, comparisons between temperate grasslands displaying marked seasonal changes in biomass and tropical grasslands (where biomass may not change much despite high turnover) should be avoided

\section{5 and 6. Sum of positive increments in} live and dead plus litter

SUM (positive increments in Agbmass Singh et al. (1975)

+ Stdead OR AGTotdead)

Assumptions: simultaneous growth, death and decomposition (i.e. continuous turnover) does not occur; NPP is never negative during a sample interval; belowground production may be similarly measured, ignored altogether, or estimated only as a fraction of aboveground production using a crude root/shoot ratio. Method 5 assumes mortality is manifest as changes in standing dead matter only; Method 6 counts changes in total dead matter.

Conclusions: same as for Method 2, although the correction for material lost by death during periods of biomass increase will reduce the degree of underestimation of NPP 


\begin{tabular}{|c|c|c|c|}
\hline Method & Description & Calculation & Reference \\
\hline & $\begin{array}{l}\text { um of changes in live and } \\
\text { ead biomass with adjustment } \\
\text { or decomposition }\end{array}$ & $\begin{array}{l}\text { SUM (change in Agbmass }+ \text { change } \\
\text { in AGTotdead }+[\text { Agr } \times \text { AGTotdead }])\end{array}$ & $\begin{array}{l}\text { Long et al. (1989); after Weigert \& Evans } \\
\text { (1964) }\end{array}$ \\
\hline & \multicolumn{3}{|c|}{$\begin{array}{l}\text { Assumptions: measured changes in parameters are statistically significant over each sample interval (in practice, this may be } \\
\text { very hard to achieve, since an impractically large number of samples would be required to detect real but modest changes over } \\
\text { each sampling interval); decomposition rate is independent of the composition of dead matter (in fact, it will decline } \\
\text { exponentially as a function of lignin: } \mathrm{N} \text { ratio); losses of AGbiomass and AGTotdead by grazing, root exudation, etc. are } \\
\text { negligible; belowground production may be similarly measured, or estimated only as a fraction of aboveground production } \\
\text { using a crude root/shoot ratio }\end{array}$} \\
\hline & \multicolumn{3}{|c|}{$\begin{array}{l}\text { Conclusions: this is the only method which incorporates all components required for an accurate estimate of NPP (and then } \\
\text { only if both above- and belowground production are measured); not available for all study sites, but it provides a useful } \\
\text { benchmark against which to check the possible degree of underestimation using other methods; where detailed biomass } \\
\text { dynamics are available but no data exists on decomposition or disappearance of dead matter, it may be possible to improve on } \\
\text { estimates by modelling decomposition using data from other similar sites }\end{array}$} \\
\hline
\end{tabular}

Names of variables:

Agbmass = Aboveground live matter; Bgbmass = Belowground live root matter; AGTotclp = Aboveground total, live + dead; AGTotmat $=$ Aboveground total, live + dead; AGTotdead $=$ Aboveground total dead matter $=$ Stdead + litter; Agr $=$ Aboveground relative rate of decomposition; AGTotclp $=$ Aboveground total clipped matter $=$ AGbmass + Stdead; BGTotmat $=$ Belowground total, live + dead; Stdead $=$ Standing dead matter; Litter $=$ Dead matter on ground; Crown $=$ biomass of plant crowns (IBP sites), added to agbmass; Newdead = 'New' dead matter, assumed to be standing; Olddead ='Old' dead matter, assumed to be litter; AGTotded = Total dead matter, Stdead + litter; Bgdead $=$ Belowground dead root matter.

and belowground compartments, at three terrestrial tropical grassland sites (Method 7). Monthly losses were determined as the change in dead matter plus the estimated disappearance of dead matter through decomposition. Using this methodology, NPP estimates were three to five times higher for these grasslands than would have been obtained at the time of the IBP (Long et al., 1989).

Singh et al. (1975) showed that although many of the aboveground NPP (ANPP) estimates obtained using different computational methods were correlated with one another, they may yield significantly different figures when applied to the same set of data. They raised concerns about the statistical significance of differences in measured biomass between successive harvests, but acknowledged that strict statistical constraints could prove 'logistically prohibitive'. Although statistical procedures exist for determining the optimum number and size of quadrats for sampling within desired tolerances, it is generally not practicable to maximize the number of quadrats so as to obtain a statistically significant difference in biomass between consecutive samples (Long et al., 1992). The problem remains that the degree of underestimation using different methods may be strongly site-specific (Linthurst \& Reimold, 1978). Yet another possibility is that the degree of underestimation may vary with year of measurement.

Both the magnitude and the ranking of NPP estimates across different study sites and biomes may have important consequences. The role of grasslands alongside other biome types may be misjudged, in terms of their relative contribution to the global carbon cycle and consequences of climate change. Grasslands destined for conversion to agriculture may be undervalued, or algorithms for estimating NPP by remote sensing may be poorly parameterized if the 'calibration' estimates of NPP are based upon an inappropriate method (Long et al., 1989). Furthermore, the body of knowledge of NPP of grasslands still rests largely upon IBP estimates, yet a number of global NPP models tend to produce higher NPP estimates for grasslands, suggesting a model-data mismatch and perhaps incorrectly a shortcoming of the models (A. W. King, pers. comm.) Grasslands occupy one-fifth of the Earth's land surface, so they are probably major players in the global carbon cycle alongside forests and should not be overlooked (Scurlock \& Hall, 1998).

\section{Methods}

We compared different NPP estimation methods or algorithms (Table 2) across an extensive range of grassland study sites, in order to demonstrate how the choice of method affects both the magnitude and the ranking of NPP estimates. Our analysis is similar to that performed by Singh et al. (1975) for data from 10 grassland sites within the US-IBP Grassland Biome Program. However, the present study involves 31 study sites from a wider range of grassland types around the world (Fig. 1; Table 1), including most of those previously analysed by Singh et al. (1975). Singh et al. (1975) were limited to the three years of the IBP Grassland Biome campaign 


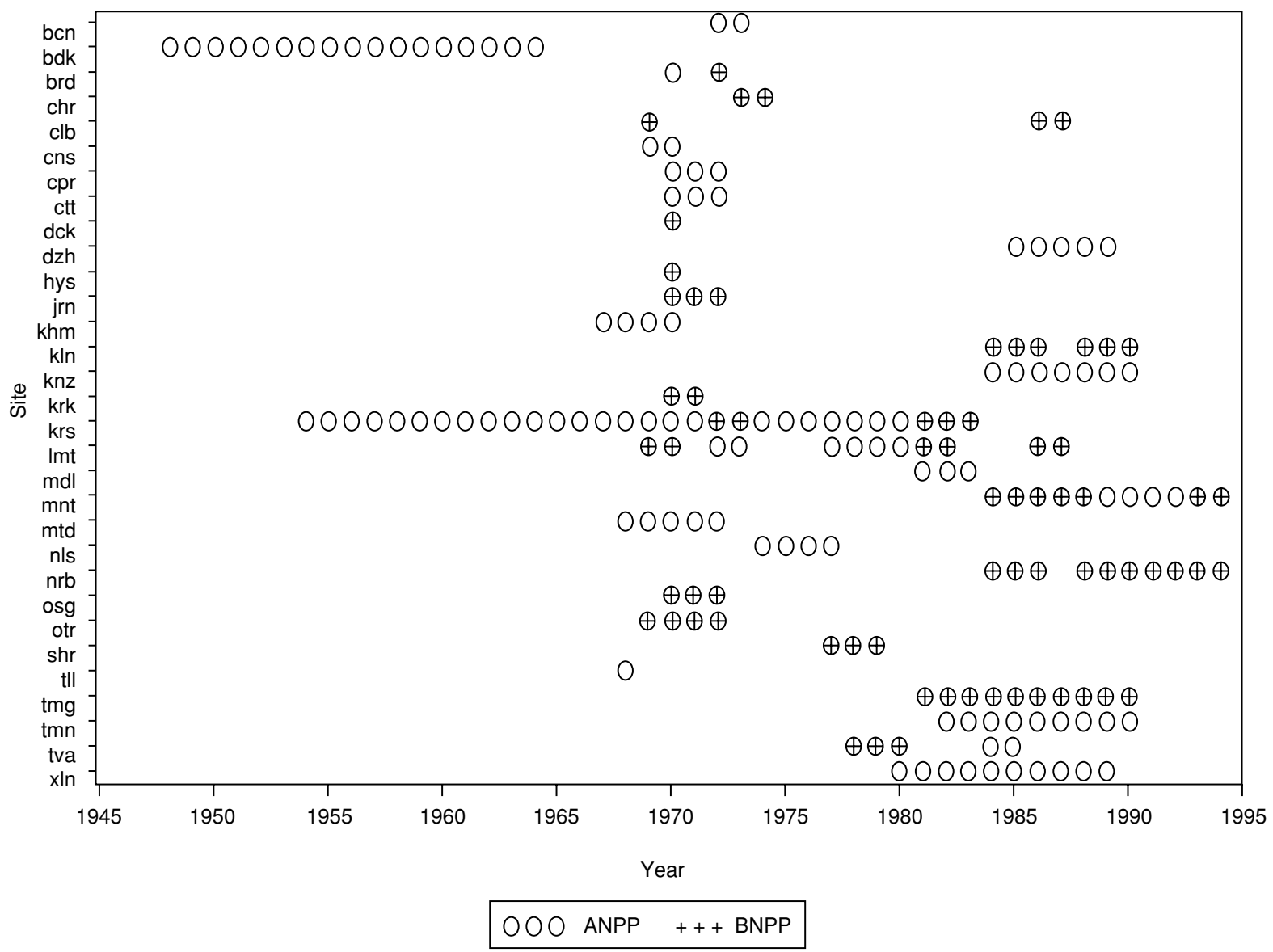

Fig. 2 Temporal coverage of NPP measurements at the grassland sites included in this analysis, listed in alphabetical order of site code (see Table 1 for site names). ANPP = aboveground NPP; BNPP = belowground NPP. Some study sites have long records over many years, whereas others were subject to relatively short field measurement campaigns. The earliest measurements date from the late 1940s, with a peak of activity during the International Biological Program (mid 1960s to mid 1970s) and a number of new study sites added during the 1980s. Estimates of NPP are rarely available across the majority of sites for any specified range of years, and most measurements do not coincide with the availability of satellite-derived vegetation indices (1980s-1990s) commonly used for global modelling. In many instances, the best that may be done - for the purposes of model parameterization and/or validation - is to provide an average NPP value 'for the late 20th century', with some idea of its likely interannual variability.

(1970-72), whereas the data we analysed cover a greater range of years and hence interannual variability (1948-94), and are therefore more truly representative. The total number of individual field measurements or 'data points' representing components of NPP was 1477. The study sites had from one to 30 years of data with an average of 6 years per site (Fig. 2). About half the data were collected in the 14-year period from 1977 to 1990. For part of our analysis, we grouped the grassland study sites into the following five ecoregions, after Bailey (1989): cold steppe, temperate dry steppe, humid savanna, humid temperate, and savanna.

The selection of study sites for inclusion in the present analysis was based upon the availability of complete and consistent information on NPP or at least partial NPP, together with the dynamics of live biomass and dead matter for at least the growing season (Scurlock \& Olson 2001). Site-description metadata, such as latitude, longitude and elevation, information on vegetation type (biome), soil type and land-use history were also desirable. At least one reference was preferred from the peerreviewed literature. Quality assurance (QA) included plotting the points in geographical space to confirm that they coincided with landforms, and checking data ranges for outlying values. For consistency, only measurements from long-term unmanaged sites without grazing were used in the present study. Of the grassland study sites in the ORNL DAAC archive, 31 met the criteria for inclusion 
Table 3 Reported biomass dynamics parameters for 31 grassland sites worldwide, in alphabetical order of site name. Agbiomass = aboveground live biomass; Stdead = standing dead matter; litter = litter (not attached to standing vegetation); Agtotmat = aboveground total matter; Bgbiomass = belowground live biomass (roots and rhizomes); Bgdead = belowground dead matter; Bgtotmat = belowground total matter. In addition, the parameters AGr and BGr (decomposition rates of aboveground and belowground matter, respectively) were reported independently for a single study site in the ORNL DAAC archive (Montecillo, Mexico)

\begin{tabular}{|c|c|c|c|c|c|c|c|c|}
\hline $\begin{array}{l}\text { Site } \\
\text { code }\end{array}$ & Name & AGbiomass & Stdead & litter & AGtotmat & BGbiomass & BGdead & Bgtotmat \\
\hline bdk & Badkhyz & + & - & - & - & - & - & - \\
\hline bcn & Beacon Hill & + & - & - & + & - & - & - \\
\hline brd & Bridger & + & - & - & + & - & - & + \\
\hline $\mathrm{clb}$ & Calabozo & + & - & - & + & - & - & + \\
\hline $\mathrm{cns}$ & Cañas & + & + & - & + & - & - & - \\
\hline $\mathrm{chr}$ & Charleville & + & - & - & - & - & - & + \\
\hline $\mathrm{ctt}$ & Cottonwood & + & + & + & + & - & - & - \\
\hline $\mathrm{cpr}$ & CPER/SGS & + & - & - & + & _- & - & _- \\
\hline dzh & Dhzanybek & + & - & - & - & - & - & - \\
\hline dck & Dickinson & + & - & - & + & - & - & + \\
\hline hys & Hays & + & - & - & + & - & - & + \\
\hline jrn & Jornada & + & - & - & + & - & - & + \\
\hline $\mathrm{khm}$ & Khomutov & + & + & + & + & - & - & - \\
\hline$k \ln$ & Klong Hoi Khong & + & + & + & + & + & + & + \\
\hline knz & Konza & + & - & - & - & - & - & - \\
\hline krs & Kursk & + & + & + & + & + & + & + \\
\hline krk & Kurukshetra & + & + & + & + & - & - & + \\
\hline $\operatorname{lmt}$ & Lamto & + & + & + & + & - & - & + \\
\hline $\mathrm{mtd}$ & Matador & + & + & + & + & - & - & - \\
\hline mdl & Media Luna & + & + & + & + & _- & - & _- \\
\hline $\mathrm{mnt}$ & Montecillo & + & - & - & + & + & + & + \\
\hline $\mathrm{nrb}$ & Nairobi & + & + & + & + & + & + & + \\
\hline nls & Nylsvley & + & - & - & - & - & - & - \\
\hline osg & Osage & + & - & - & + & - & - & + \\
\hline otr & Otradnoe & + & + & + & + & + & + & + \\
\hline $\mathrm{shr}$ & Shortandy & + & + & + & + & + & + & + \\
\hline tll & Tullgarnsnaset & + & + & + & + & _- & _- & _- \\
\hline $\mathrm{tmn}$ & Tumentsogt & + & - & - & - & - & - & - \\
\hline $\mathrm{tmg}$ & Tumugi & + & - & - & - & + & - & - \\
\hline tva & Tuva & + & + & + & + & + & - & - \\
\hline$x \ln$ & Xilingol & + & _- & - & - & - & _- & _- \\
\hline \multicolumn{2}{|c|}{$\%$ reporting (to 2 figures) } & 100 & 45 & 42 & 74 & 26 & 19 & 48 \\
\hline
\end{tabular}

in the present analysis. One of the 31 sites (Kurukshetra, India; Singh and Yadava, 1974), was later excluded from the analysis because it appears to be an 'outlier' with very high NPP. This may be a consequence of some undocumented factor such as a previous history of fertilization at the study site, but since Kurukshetra meets all other criteria for inclusion in this analysis, it is described and tabulated to illustrate a typical problem of QA and outlier checking.

The data tabulated for each site consisted of monthly measurements of biomass components including aboveground live material, standing dead, litter, belowground biomass, and belowground dead material. However, many of the sites did not collect all of the components. On average, there were about 24 discrete measurement dates per site, all sites having at least aboveground biomass measurements (Table 3 ). Of the 31 sites, 23 also reported the dynamics of standing dead matter and litter, or total dead matter. This is important, since it has been argued that grassland productivity should be assessed based upon the dynamics of both live and dead matter together, rather than live matter alone (Singh et al., 1975; Linthurst \& Reimold, 1978; Long et al., 1989, 1992). In addition, 17 studies reported belowground live or total biomass, although only six sites had data for both live and dead root matter. It has been previously emphasized that estimates of belowground NPP (BNPP) are critically important in assessing grassland productivity (Long et al., 1989; Scurlock \& Hall, 1998). 
We calculated annual NPP based upon calendar years (January-December) but we recognize that annual NPP may be estimated for any appropriate 12-month growing cycle, depending on latitude (Northern or Southern hemisphere growing season) and the environmental or management factors which determine this cycle. For example, yearly burning during a short dry season is an important 'scheduling' factor in many humid savannas (Menaut \& Cesar, 1979; Kamnalrut \& Evenson, 1992). We also noted that the length of the growing season varied widely, from as little as three months in extreme continental or semiarid conditions to as much as 12 months in some humid tropical regions. In certain cases (e.g. East Africa) precipitation may be bi-modal, leading to two growing seasons per year.

NPP estimates for seven algorithms (Table 2) were computed using the SAS ${ }^{\mathrm{TM}}$ V6.02 software package (the SAS ${ }^{\mathrm{TM}}$ code is available from the authors). SAS ${ }^{\mathrm{TM}}$ was also used to process the original grassland biomass observations to generate data sets for each site that had common variable names, units of measure, and organization. For example, we assumed that the variables described in the original literature as 'standing dead', 'recent dead', and 'new dead' were equivalent, representing plant matter which was produced and died within the current year, and that the variables 'old dead' and 'litter' usually represent the accumulation of previous years' dead matter. Some sites lacked desired information, such as the day of the month that measurements were recorded, or required decisions to assemble the data, such as combining above- and belowground measurements when the components were measured on different days. Where possible, we examined the original literature or contacted the authors to confirm our assumptions in documenting these data (Scurlock \& Olson, 2001).

Checks were included to determine if adequate measurements were available for a site to estimate NPP for each method. For example, if standing dead matter was not measured at a site, then NPP was not estimated by Methods 3, 5 and 6, and if only aboveground measurements were available, then only ANPP was estimated. We found that only one study site (Montecillo, Mexico) had reported monthly decomposition rates for dead matter (and two others - Nairobi, Kenya and Klong Hoi Khong, Thailand - had reported NPP accounting for decomposition by Method 7), so we excluded Method 7 from the overall analysis. Nevertheless, Method 7 does provide a useful benchmark against which to check the possible degree of underestimation using other methods.

Above- and belowground data were processed separately and, if measurements for both components were available, they were summed to provide total NPP for the site. In computing the cumulative annual NPP, sites with less than five biomass measurements for a year were dropped to ensure that the entire growing season was represented (assuming that most sites reported biomass dynamics approximately monthly).

We used descriptive and multivariate statistics to compare sites, methods, and years (Figs 3 and 5). Analysis of variance was performed to test differences among NPP Methods within ecoregions to determine their influence in estimating ANPP. We used the general linear model procedure (SAS ${ }^{\mathrm{TM}}$ V6.12) to accommodate the unbalanced set of observations. The most consistent and balanced subset of data was between 1970 and 1972 during the intensive IBP Grassland Biome Program. Data were available for 15 different sites in 4 of the 5 ecoregions, with 2-3 years of biomass measurements for each site, enabling NPP estimation by all 6 methods. Sites and years were used to estimate within-group variances. We realize that the NPP methods are not completely independent; however, most methods include a component not represented in the other methods. Duncan's Multiple Range test (SAS ${ }^{\mathrm{TM}}$ V6.12; Snedecor and Cochran, 1980) was used to determine differences within methods and ecoregions.

\section{Results}

As mentioned above, aboveground live biomass was the most commonly reported of the parameters describing the dynamics of grasslands (Table 3), so Method 1 was used to rank the sites by NPP (Fig. 4). It is notable that in Fig. 4(a), all six algorithms show a general trend of diminishing ANPP from left to right. However, the ranking of the study sites would change quite markedly if, for example, aboveground total matter (Method 2; ANPP2) or the sum of increments in live and dead matter (Method 4; ANPP4) were used to rank the sites instead of aboveground peak live biomass (Method 1; ANPP1). For example, the study sites Matador (mtd) and Tuva (tva) have adjacent ranking (25th and 26th) in terms of NPP using Method 1; yet if Method 2 or Method 5 were used to estimate NPP, Matador would be promoted to the 'Top 10', whilst Tuva's ranking would remain largely unchanged.

Similar changes in ranking with different NPP methods would also apply to belowground NPP (Fig. 4b) or total NPP (Fig. 4c). Belowground productivity, which is commonly ignored altogether in grasslands or assumed equal to a particular fraction of aboveground productivity, varied considerably between study sites and had a significant impact upon the ranking of productivity (compare Fig. 4; a, b and c). For example, Tumugi, China (tmg in Fig. 4), is ranked only 20th out of 31 in terms of aboveground NPP by Method 1, yet 3rd 
744 J. M. O. SCURLOCK et al.

(a)

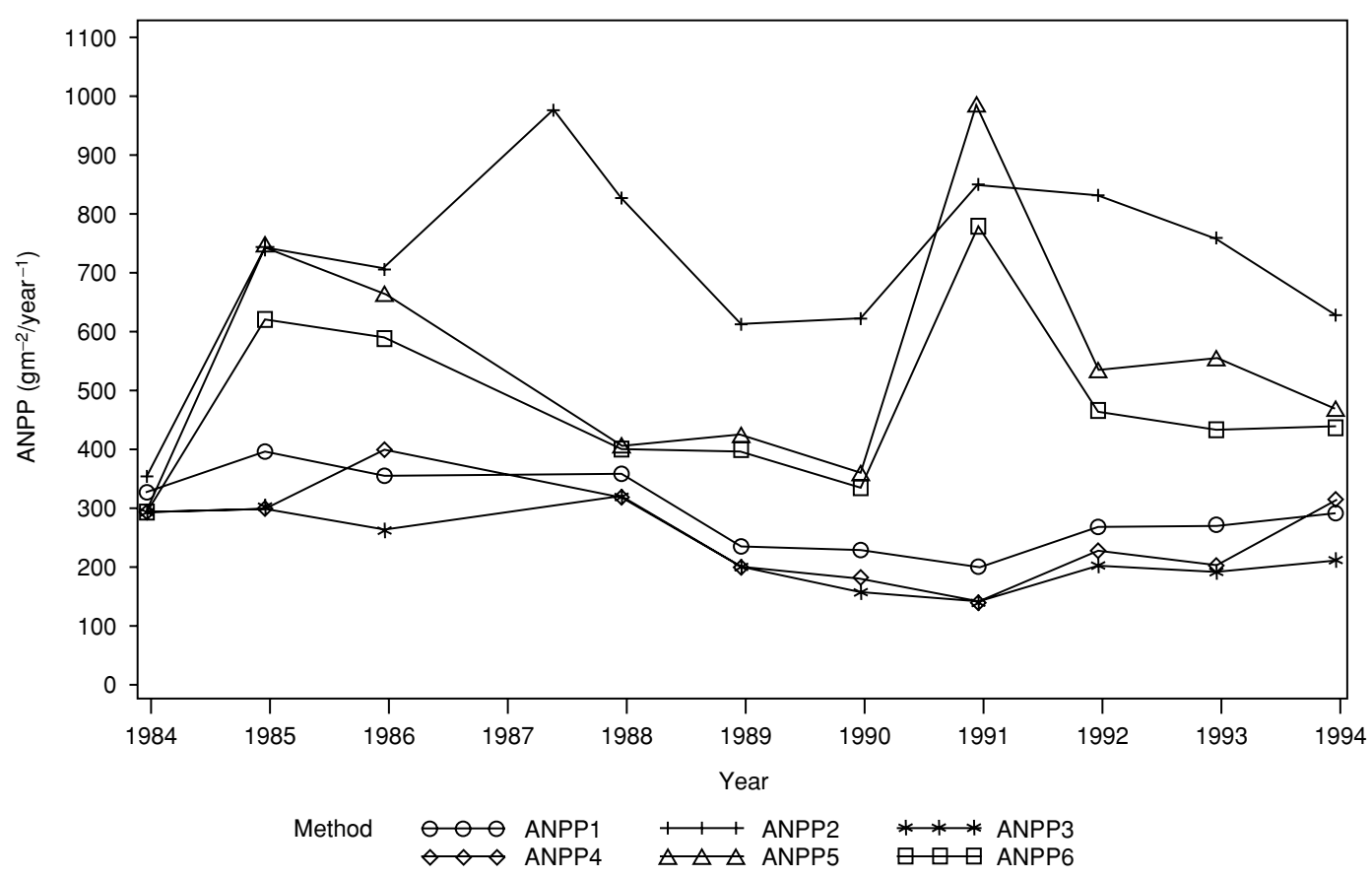

(b)

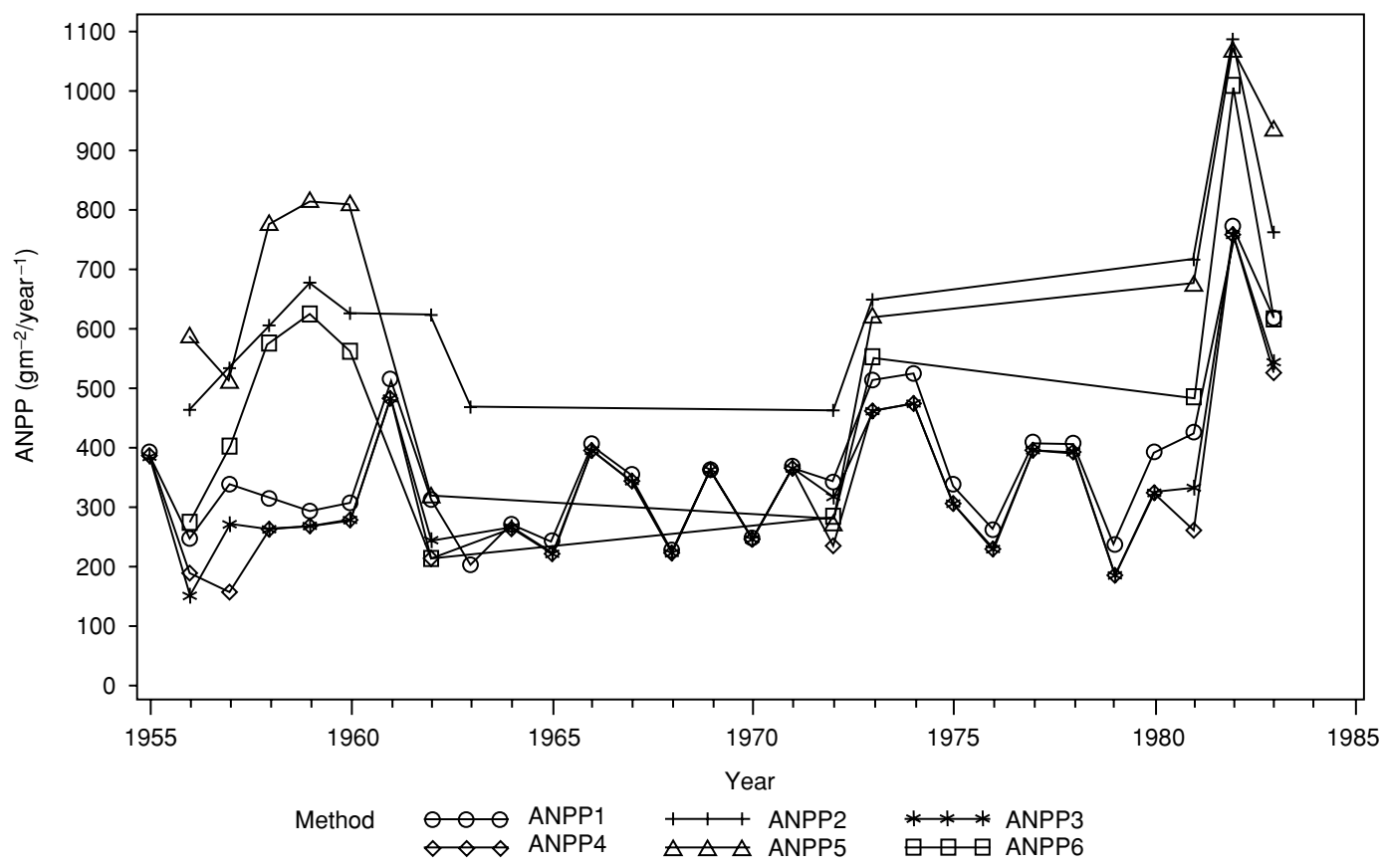

Fig. 3 Year-to-year variation in estimates of aboveground NPP (ANPP) using six different algorithms for (a) a grassland study site where NPP is limited mostly by water availability (Nairobi, Kenya), and (b) a grassland study site where NPP is limited mostly by temperature (Kursk, Russia). Note the discrepancy between those algorithms which include the dynamics of dead matter (Methods 2, 5 and $6=$ ANPP2, ANPP5 and ANPP6), and those which count only live biomass (Methods 1, 3 and $4=$ ANPP1, ANPP3 and ANPP4). The latter group have very similar estimates from year to year, and the interannual range is not as great. The magnitude of ANPP is evidently greater, and interannual variation in ANPP tends to be larger, for those algorithms which include dead matter. N.B. in Fig. 3(a), there are no data for 1987, and in Fig. 3(b) the reduced number of data points for certain methods, e.g. Method 2, is indicative of less data available. 
(out of 8) in terms of belowground NPP by Method 1, and then 4 th for total NPP.

The NPP methods showed statistical similarity among ecoregion groupings, according to which methods account for changes in dead matter and which methods are based on the dynamics of aboveground live biomass only (Figs 3 and 5). Based upon our analysis of variance for sites having data for the period 1970-1972, NPP Methods 2 and 5 were not significantly different from one another for ecoregions $(P=0.05)$, nor were Methods 1, 3, and 4 significantly different. These two groups were significantly different from each other, even after considering interannual climate differences, based on Duncan's Multiple Range Test (Snedecor \& Cochran, 1980). Method 6 fell in between the two groups.

Based on the components included, practical considerations of field techniques, and our results, NPP Method 5 appears to be an adequate predictor of NPP across all ecoregions. It also generally gave the highest estimates of NPP. One way therefore to characterize the differences between NPP methods is to calculate the ratio of NPP Method 5 to the more common NPP Method 1. The overall ratio was 1.88 , which is indicative of the overall degree of discrepancy likely between different sources of NPP estimates. However, there was a considerable range of ratios (0.17-6.53) indicating greater discrepancies at individual sites. When we grouped the ratios by ecoregions, the ratio for the dry steppes (2.61) was significantly higher than that for the cold steppes (1.28), with the other ecoregions grouped between the extremes.

We also compared NPP Method 5 with the most complex NPP estimation method (Method 7) for a subset of three study sites, including savannas and humid savannas (Table 4). These three sites had measured all the components, including decomposition rates, to permit estimation of NPP by both methods for selected years. Although no overall pattern of differences was discernible in either mean values or ranges of ANPP, a paired $t$-test comparison between Method 5 and Method 7 by year showed that total NPP by Method 7 was significantly lower than Method $5(P=0.05)$. This difference ranged from 5 to $23 \%$. Further statistical tests confirmed that ANPP was not significantly different between the two methods, and that the main difference lay in the estimates of belowground productivity.

Where sufficient data existed for a determination, the proportion of total NPP occurring belowground (BNPP/ NPP, estimated by Method 5; Table 5) ranged from 0.40 in a savanna site to 0.88 for a cold steppe. These results may also be expressed in terms of the BNPP/ANPP ratio, which ranged from 0.67 to 7.3 . The corresponding average ratios of belowground to total biomass (based preferably on live biomass, otherwise on total standing crop)
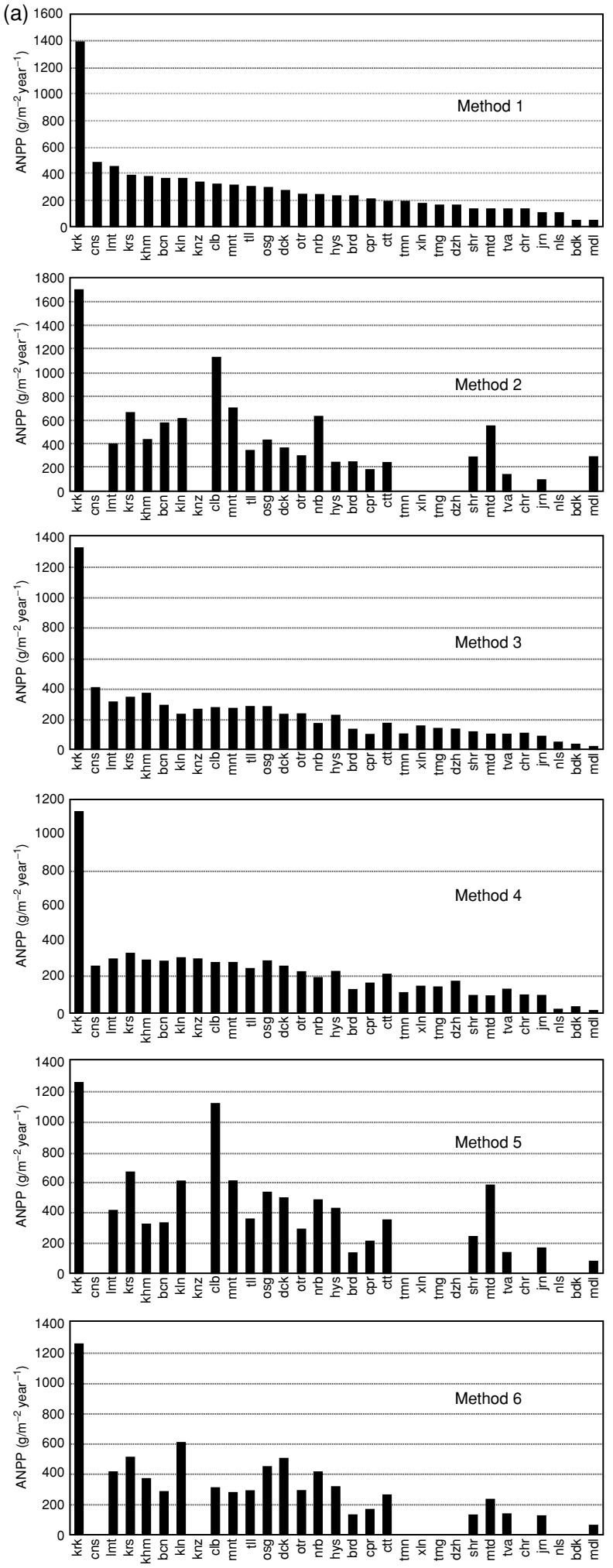
(b)
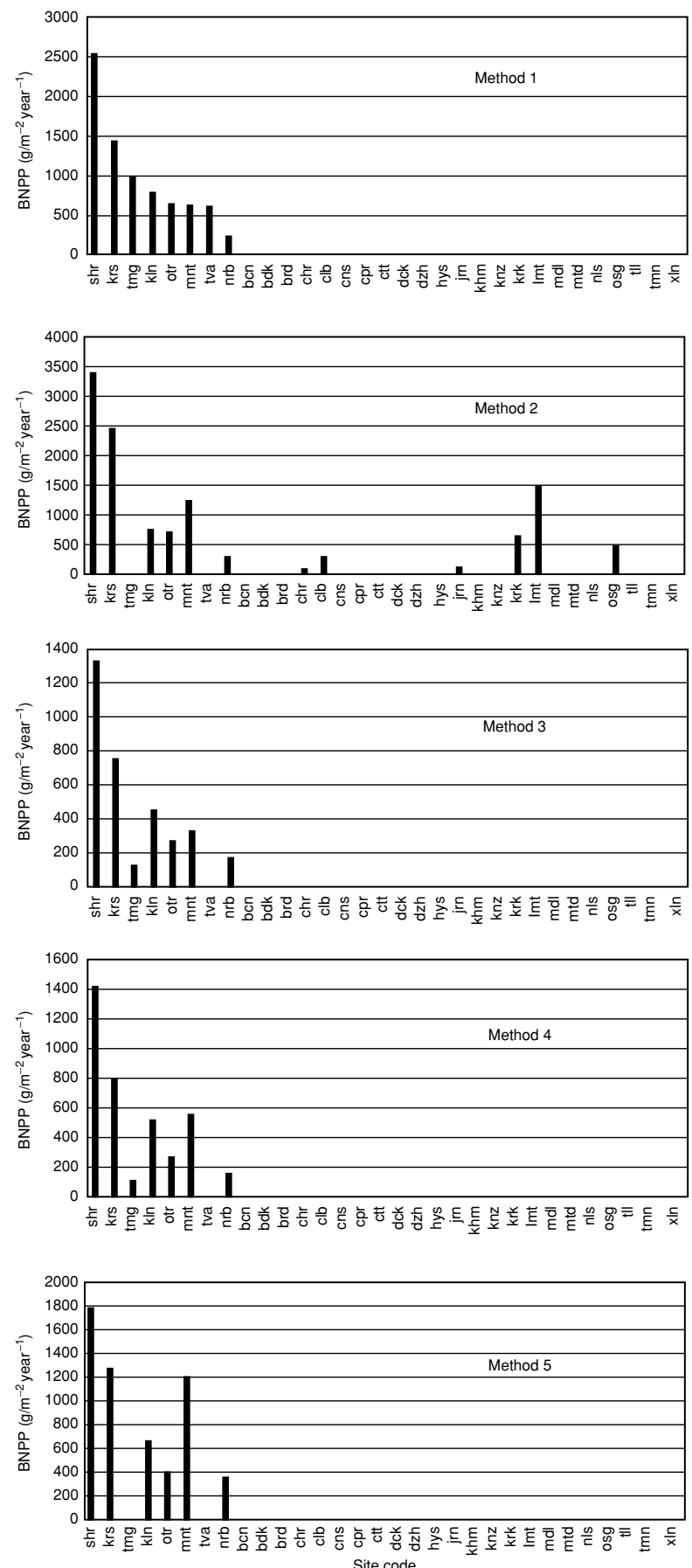

(c)
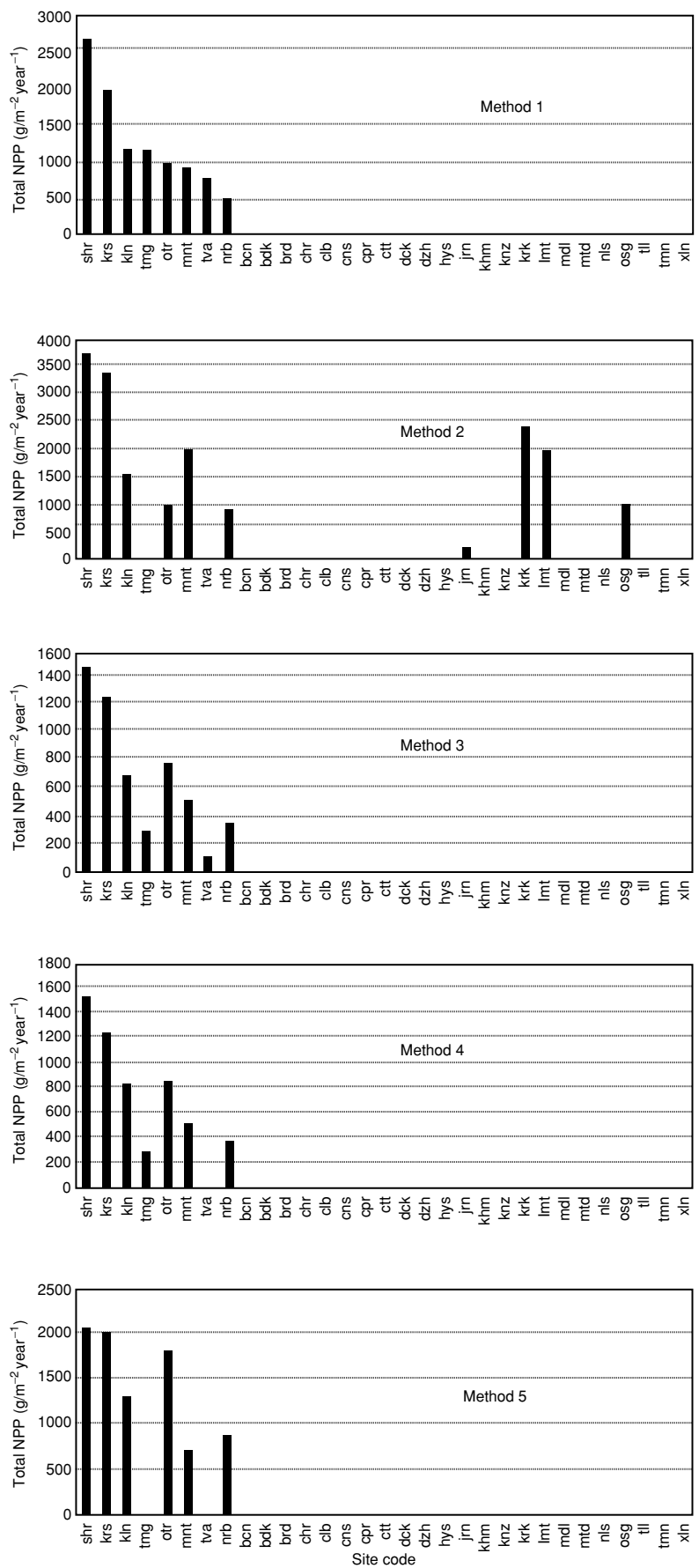

Fig. 4 (a) Aboveground net primary productivity (ANPP) estimated using six different ANPP algorithms (Methods 1-6) across 31 grassland study sites, ranging from the humid tropics to dry continental conditions. The sites are ranked here by Method 1, i.e. peak aboveground live biomass, one of the simplest and most commonly applied 'indicators' of ANPP; (b) Belowground net primary productivity (BNPP) estimated using five different ANPP algorithms (Method 1 to Method 5) for 14 of the 31 grassland study sites. Sites are ranked by Method 1, i.e. peak belowground live biomass. Again, note that the ranking of the study sites would change quite markedly if other algorithms (Method 2 to Method 5) were used to determine BNPP; (c) Total net primary productivity (NPP; equals ANPP + BNPP) estimated using five different algorithms (Method 1 to Method 5) for 12 of the 31 grassland study sites. Sites are ranked by Method 1, i.e. the sum of peak aboveground and peak belowground live biomass. See Table 1 for relationship of site codes to study site names. 
(a)

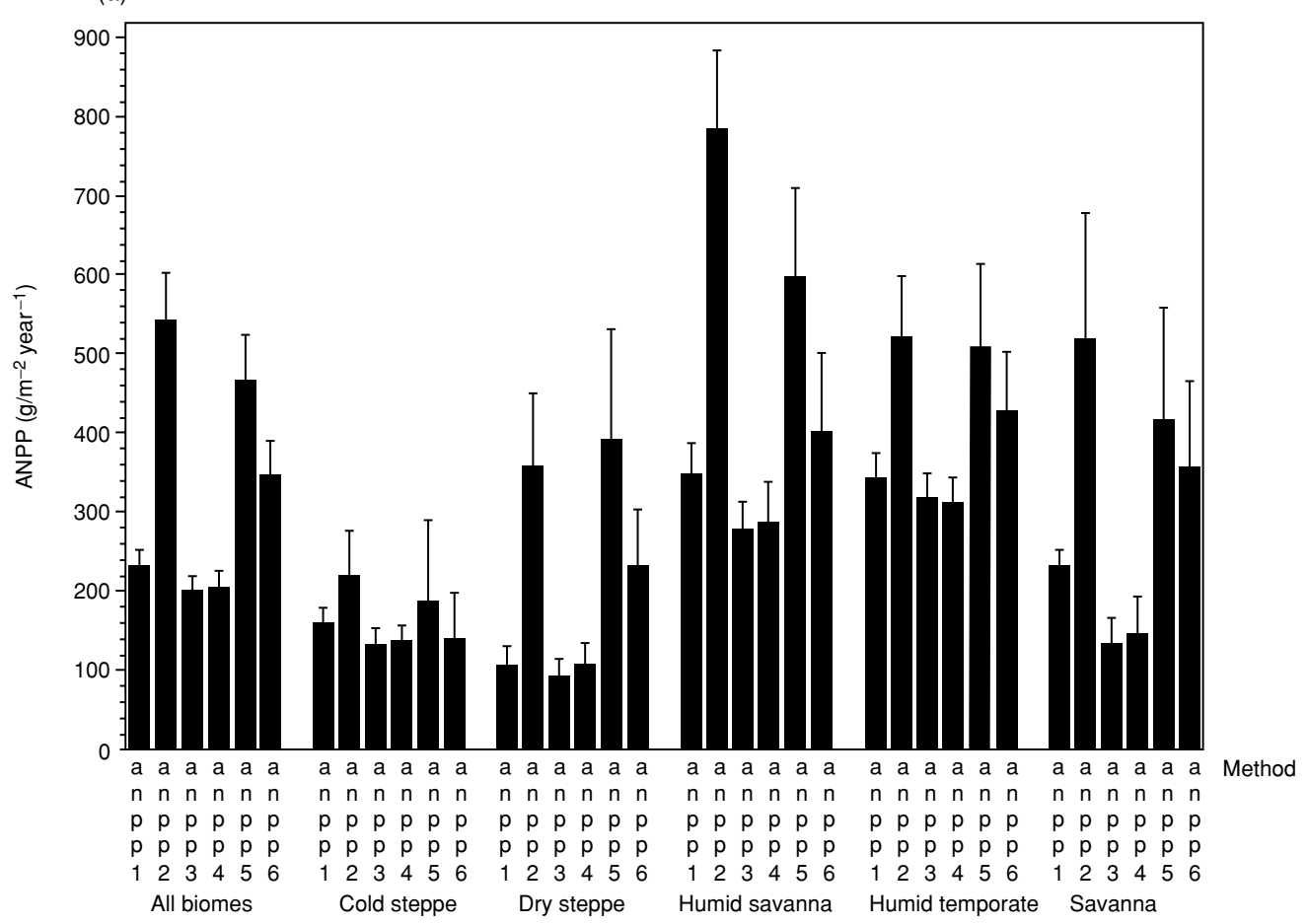

(b)

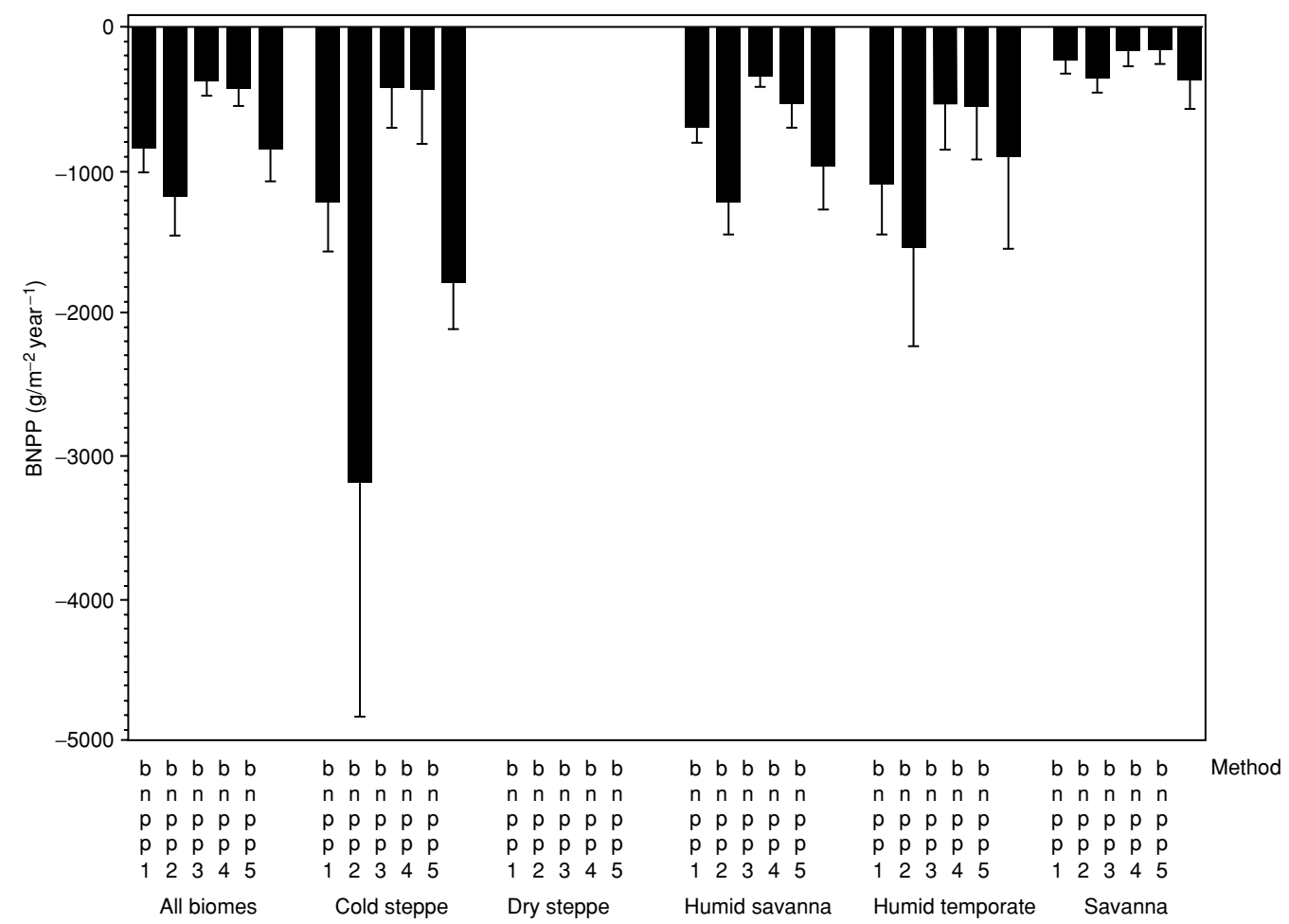

Fig. 5 Illustration of the degree of difference in (a) average ANPP estimates; and (b) average BNPP estiamtes obtained with the six methods for different ecoregions, and for all ecoregions (after Bailey, 1989). The number of (sites $\times$ years) for each (ecoregion $\times$ method) ranged from 7 to 49. Again, it is evident that Methods 1, 3 and 4 yield similar NPP estimates, whilst Methods 2, 5 and 6 yield generally greater NPP estimates, with this difference being least marked in the cold steppe ecoregion, and most marked in savannas and humid savannas. N.B. Methods 5 and 6 are identical for belowground NPP, hence only Method 5 is shown in (b). Error-bars represent 95\% confidence intervals. 
748 J. M. O. SCURLOCK et al.

Table 4 Yearly minimum, maximum, and mean values for ANPP and total NPP at three tropical grassland study sites where Method 5 (Singh et al. 1975) could be compared with Method 7 (Long et al. 1989)

\begin{tabular}{|c|c|c|c|c|c|c|c|}
\hline Site name & $\begin{array}{l}\text { NPP } \\
\text { method }\end{array}$ & $\begin{array}{l}\text { ANPP } \\
\min \\
\left(\mathrm{g} \mathrm{m}^{-2} \text { year }^{-1}\right)\end{array}$ & $\begin{array}{l}\text { ANPP } \\
\max \\
\left(\mathrm{g} \mathrm{m}^{-2} \text { year }^{-1}\right)\end{array}$ & $\begin{array}{l}\text { ANPP } \\
\text { mean } \\
\left(\mathrm{g} \mathrm{m}^{-2} \text { year }^{-1}\right)\end{array}$ & $\begin{array}{l}\mathrm{NPP} \\
\mathrm{min} \\
\left(\mathrm{g} \mathrm{m}^{-2} \text { year }^{-1}\right)\end{array}$ & $\begin{array}{l}\mathrm{NPP} \\
\max \\
\left(\mathrm{g} \mathrm{m}^{-2} \text { year }^{-1}\right)\end{array}$ & $\begin{array}{l}\mathrm{NPP} \\
\text { mean } \\
\left(\mathrm{g} \mathrm{m}^{-2} \text { year }^{-1}\right)\end{array}$ \\
\hline \multirow{2}{*}{$\begin{array}{l}\text { Klong Hoi Khong } \\
(n=3)\end{array}$} & Method 5 & 540 & 895 & 744 & 960 & 1712 & 1412 \\
\hline & Method 7 & 404 & 1430 & 1083 & 134 & 1676 & 1148 \\
\hline \multirow{2}{*}{$\begin{array}{l}\text { Montecillo } \\
(n=6)\end{array}$} & Method 5 & 379 & 996 & 563 & 1033 & 2659 & 1885 \\
\hline & Method 7 & -563 & 938 & 505 & 105 & 1964 & 1456 \\
\hline \multirow{2}{*}{$\begin{array}{l}\text { Nairobi } \\
(n=2)\end{array}$} & Method 5 & 610 & 695 & 653 & 854 & 1597 & 1226 \\
\hline & Method 7 & 331 & 885 & 609 & 1132 & 1188 & 1160 \\
\hline
\end{tabular}

Table 5 Proportion of NPP belowground (BNPP/total NPP; minimum, maximum and mean) estimated for 15 study sites with sufficient data (total of 64 site-years). Ratio 1-2 = calculated according to Method 1/Method 2 (peak live, or otherwise peak total biomass). Ratio $5=$ calculated according to Method 5 (positive increments, including dead matter dynamics). See text and Table 2 for numbering of NPP methods. ${ }^{* *}=$ insufficient data for calculation

\begin{tabular}{|c|c|c|c|c|c|c|c|}
\hline Site code (Method used) & Name & $\begin{array}{l}\text { Ratio1-2 } \\
\text { min }\end{array}$ & $\begin{array}{l}\text { Ratio1-2 } \\
\max \end{array}$ & $\begin{array}{l}\text { Ratio 1-2 } \\
\text { mean }\end{array}$ & $\begin{array}{l}\text { Ratio } 5 \\
\min \end{array}$ & $\begin{array}{l}\text { Ratio } 5 \\
\max \end{array}$ & $\begin{array}{l}\text { Ratio } 5 \\
\text { mean }\end{array}$ \\
\hline \multicolumn{8}{|l|}{ COLD STEPPE } \\
\hline brd (2) & Bridger & 0.84 & 0.84 & $0.84(n=1)$ & $* *$ & ** & $* *$ \\
\hline $\operatorname{shr}(1)$ & Shortandy & 0.93 & 0.96 & $0.95(n=3)$ & 0.85 & 0.94 & $0.88(n=3)$ \\
\hline $\operatorname{tmg}(1)$ & Tumugi & 0.82 & 0.96 & $0.87(n=10)$ & $* *$ & $* *$ & $* *$ \\
\hline tva (1) & Tuva & 0.75 & 0.90 & $0.84(n=3)$ & $* *$ & $* *$ & $* *$ \\
\hline \multicolumn{8}{|l|}{ TEMPERATE DRY STEPPE } \\
\hline hys (2) & Hays & $\begin{array}{l}0.70 \\
0.93\end{array}$ & 93 & $0.93(n=1)$ & $* *$ & $* *$ & $* *$ \\
\hline \multicolumn{8}{|l|}{ HUMID SAVANNA } \\
\hline $\mathrm{clb}(2)$ & Calabozo & 0.18 & 0.18 & $0.18(n=1)$ & $* *$ & $* *$ & $* *$ \\
\hline$k \ln (1)$ & $\begin{array}{l}\text { Klong Hoi } \\
\text { Khong }\end{array}$ & 0.52 & 0.76 & $0.68(n=6)$ & 0.44 & 0.65 & $0.51(n=6)$ \\
\hline $\operatorname{lmt}(2)$ & Lamto & 0.62 & 0.79 & $0.70(n=6)$ & $* *$ & $* *$ & $* *$ \\
\hline mnt (1) & Montecillo & 0.52 & 0.73 & $0.66(n=7)$ & 0.46 & 0.78 & $0.66(n=7)$ \\
\hline \multicolumn{8}{|l|}{ HUMID TEMPERATE } \\
\hline krs (1) & Kursk & 0.70 & 0.80 & $0.73(n=5)$ & 0.21 & 0.71 & $0.58(n=5)$ \\
\hline osg (2) & Osage & 0.61 & 0.78 & $0.68(n=3)$ & $* *$ & $* *$ & $* *$ \\
\hline otr (1) & Otradnoe & 0.64 & 0.78 & $0.72(n=4)$ & 0.23 & 0.73 & $0.55(n=4)$ \\
\hline \multicolumn{8}{|l|}{ SAVANNA } \\
\hline jrn (2) & Jornada & 0.58 & 0.77 & $0.67(n=3)$ & $* *$ & $* *$ & $* *$ \\
\hline $\operatorname{nrb}(1)$ & Nairobi & 0.30 & 0.76 & $0.46(n=10)$ & 0.15 & 0.62 & $0.40(n=10)$ \\
\hline
\end{tabular}

ranged from 0.46 to 0.95 across the same ecoregions (i.e. a root/shoot ratio from 0.85 to 19 ). Some differences in allocation of NPP could be perceived between different ecoregions (lower allocation of root production in warmer and more humid environments). Based on the $\mathrm{BNPP} / \mathrm{NPP}$ ratio using Methods 1 or 2 (total of 64 siteyears in 5 ecoregions; Table 5), we found significant differences according to Duncan's Multiple Range test. The cold steppe and dry steppe ecoregions were similar (average of 0.86), the humid temperate and humid savanna ecoregions were similar (average of $0.69)$, and the savanna ecoregion has the lowest ratio (0.51).

\section{Discussion}

Given that peak live biomass is widely reported as a measurement (Table 3 ), it is hardly surprising that it is 




Fig. 6 Box-and-whisker plot showing likely degrees of under-estimation of ANPP, by ecoregion (after Bailey, 1989), as suggested by the ratio of the highest ANPP estimate (Method 5) to the lowest (Method 1). Group medians (centre line), means ( $\triangle$ ), 25 and 75 percentiles (top and bottom of box), range of data up to 1.5 interquartile ranges (whiskers), and extreme values (+). A range of $1-3 \times$ appears most common, but up to $6 \times$ or more is possible in grassland ecoregions characterized by the accumulation of dead matter (temperate dry steppes and savannas).

also commonly used as an indicator of grassland productivity. However, both the magnitude and the ranking of productivity between different study sites has been shown to change significantly when more elaborate indicators of productivity are applied (Singh et al., 1975; Long et al., 1989). In the present study, the precise ranking of the 31 grassland sites by productivity changed, depending upon which NPP algorithm was used (Fig. 4). Nevertheless, the predominance of the taller (more productive) histogram bars to the left of Fig. 4 suggests that peak biomass (Method 1) is a fair indicator of rank in productivity.

It is more worrying that the quantitative NPP estimates obtained using the more complex algorithms are up to $2-5$ times higher than would be obtained using the most commonly applied estimate (peak live biomass; Method 1 ), and moreover, that the degree of underestimation differs between grassland ecoregions (Fig. 6). This is in agreement with Singh et al. (1975), who compared a wide range of different ANPP algorithms for a smaller number of sites and found that those algorithms accounting for the dynamics of dead vegetation typically yielded between 3 and 10 times the ANPP estimate obtained from peak standing biomass alone (Method 1 of Singh et al., 1975; also Method 1, this study). Together with the sitespecific or region-specific degree of underestimation (Linthurst \& Reimold, 1978), this suggests that the relative roles of different grassland types in the global carbon cycle may indeed have been quite poorly assessed in the past (Scurlock \& Hall, 1998). 
Table 6 Ranges and 'best estimates' (minimum, maximum, and mean by year) for ANPP and total NPP for 21 of 30 grassland sites by ecoregion, and average for each ecoregion, where available. Method 5 was used where data availability permitted; otherwise Method 6 (see text and Table 2 for explanation). ${ }^{* *}=$ data insufficient for either Method 5 or 6

\begin{tabular}{|c|c|c|c|c|c|c|c|}
\hline Site name & Name & $\begin{array}{l}\text { ANPP } \\
\min \\
\left(\mathrm{g} \mathrm{m}^{-2} \text { year }^{-1}\right)\end{array}$ & $\begin{array}{l}\text { ANPP } \\
\max \\
\left(\mathrm{g} \mathrm{m}^{-2} \text { year }^{-1}\right)\end{array}$ & $\begin{array}{l}\text { ANPP } \\
\text { mean } \\
\left(\mathrm{g} \mathrm{m}^{-2} \text { year }^{-1}\right)\end{array}$ & $\begin{array}{l}\mathrm{NPP} \\
\min \\
\left(\mathrm{g} \mathrm{m}^{-2} \text { year }^{-1}\right)\end{array}$ & $\begin{array}{l}\text { NPP } \\
\max \\
\left(\mathrm{g} \mathrm{m}^{-2} \text { year }^{-1}\right)\end{array}$ & $\begin{array}{l}\mathrm{NPP} \\
\text { mean } \\
\left(\mathrm{g} \mathrm{m}^{-2} \text { year }^{-1}\right)\end{array}$ \\
\hline \multicolumn{8}{|c|}{ COLD STEPPE } \\
\hline brd & Bridger & 81 & 196 & $138(n=2)$ & $* *$ & $* *$ & $* *$ \\
\hline $\operatorname{shr}$ & Shortandy & 103 & 330 & $249(n=3)$ & 1741 & 2221 & $2032(\mathrm{n}=3)$ \\
\hline $\operatorname{tmg}$ & Tumugi & $* *$ & $* *$ & $* *$ & $* *$ & $* *$ & $* *$ \\
\hline tmn & Tumentsogt & $* *$ & ** & $* *$ & $* *$ & $* *$ & $* *$ \\
\hline tva & Tuva & 69 & 224 & $147(n=2)$ & $* *$ & $* *$ & $* *$ \\
\hline$x \ln$ & Xilingol & $* *$ & $* *$ & $* *$ & $* *$ & $* *$ & $* *$ \\
\hline \multicolumn{3}{|c|}{ OVERALL RANGE and MEAN } & 69 & 330 & $188(n=7)$ & & \\
\hline \multicolumn{8}{|c|}{ TEMPERATE DRY STEPPE } \\
\hline bdk & Badkhyz & ** & ** & $* *$ & $* *$ & $* *$ & $* *$ \\
\hline cpr & CPER/SGS & 142 & 322 & $216(n=3)$ & $* *$ & $* *$ & $* *$ \\
\hline $\mathrm{ctt}$ & Cottonwood & 334 & 383 & $362(n=3)$ & $* *$ & $* *$ & $* *$ \\
\hline dck & Dickinson & 503 & 503 & $503(n=1)$ & $* *$ & $* *$ & $* *$ \\
\hline dzh & Dhzanybek & $* *$ & $* *$ & $* *$ & $* *$ & $* *$ & $* *$ \\
\hline hys & Hays & 436 & 436 & $436(n=1)$ & $* *$ & $* *$ & $* *$ \\
\hline mdl & Media Luna & 18 & 133 & $75(n=2)$ & $* *$ & $* *$ & $* *$ \\
\hline mtd & Matador & 259 & 986 & $600(n=5)$ & $* *$ & $* *$ & $* *$ \\
\hline \multicolumn{3}{|c|}{ OVERALL RANGE and MEAN } & 18 & 986 & $388(n=15)$ & & \\
\hline \multicolumn{8}{|c|}{ HUMID SAVANNA } \\
\hline $\mathrm{clb}$ & Calabozo & 1121 & 1121 & $1121(n=1)$ & $* *$ & $* *$ & $* *$ \\
\hline cns & Cañas & $* *$ & $* *$ & $* *$ & $* *$ & $* *$ & $* *$ \\
\hline$k \ln$ & Klong Hoi Khong & 245 & 895 & $610(n=6)$ & 512 & 2012 & $1280(n=6)$ \\
\hline $\operatorname{lmt}$ & Lamto & 80 & 568 & $411(n=4)$ & $* *$ & $* *$ & ** \\
\hline mnt & Montecillo & 379 & 996 & $609(n=10)$ & 1033 & 2659 & $1783(n=7)$ \\
\hline \multicolumn{3}{|c|}{ OVERALL RANGE and MEAN } & 80 & 1121 & $518(n=21)$ & & \\
\hline \multicolumn{8}{|c|}{ HUMID TEMPERATE } \\
\hline ben & Beacon Hill & 333 & 333 & $333(n=1)$ & $* *$ & $* *$ & $* *$ \\
\hline $\mathrm{khm}$ & Khomutov & 197 & 404 & $330(n=4)$ & $* *$ & $* *$ & $* *$ \\
\hline knz & Konza & $* *$ & $* *$ & $* *$ & $* *$ & $* *$ & $* *$ \\
\hline $\mathrm{krs}$ & Kursk & 272 & 1072 & $671(n=11)$ & 768 & 3693 & $1995(n=5)$ \\
\hline osg & Osage & 291 & 710 & $540(n=3)$ & $* *$ & $* *$ & $* *$ \\
\hline otr & Otradnoe & 240 & 395 & $292(n=4)$ & 515 & 877 & $702(n=4)$ \\
\hline tll & Tullgarnsnaset & 361 & 361 & $361(n=1)$ & $* *$ & $* *$ & $* *$ \\
\hline \multicolumn{3}{|c|}{ OVERALL RANGE and MEAN } & 197 & 1072 & $508(n=24)$ & & \\
\hline \multicolumn{8}{|c|}{ SAVANNA } \\
\hline $\mathrm{chr}$ & Charleville & $* *$ & $* *$ & $* *$ & $* *$ & $* *$ & $* *$ \\
\hline jrn & Jornada & 61 & 275 & $168(n=3)$ & $* *$ & $* *$ & $* *$ \\
\hline nls & Nylsvley & $* *$ & $* *$ & $* *$ & $* *$ & $* *$ & $* *$ \\
\hline $\mathrm{nrb}$ & Nairobi & 240 & 928 & $488(n=10)$ & 422 & 1597 & $850(n=10)$ \\
\hline \multicolumn{3}{|c|}{ OVERALL RANGE and MEAN } & 61 & 928 & $414(n=13)$ & & \\
\hline
\end{tabular}

Unlike Singh et al. (1975), we found that, far from all being correlated with one another, the different NPP methods fell broadly into two groups - those which included the dynamics of dead matter, and those which ignored them (Figs 3 and 5). Nevertheless, we are in agreement that Methods 5 and 6 are preferred from both theoretical and practical point of view. Singh et al. (1975) added the condition that some statistical constraints should ideally be applied to significant differences between successive monthly biomass estimates. We also found that, at least for ANPP, Method 5 is in agreement with a more complete accounting for biomass dynamics, including mortality and decomposition (Method 7). The apparently anomalous result, that Method 5 gave higher 
estimates of belowground productivity than the more comprehensive accounting scheme implicit in Method 7, may be an example of overestimation due to the level of error implicit in monthly belowground sampling. Where there are dangers of summing changes in biomass which are not statistically significant, it may be necessary to obtain other estimates of productivity by independent methodologies (Singh et al., 1975; Biondini et al., 1991).

Table 6 shows the range and our own 'best estimates' of ANPP and total NPP obtained for the preferred method (Method 5) across as many sites as possible. Some sites were excluded by our relatively strict criteria for applying the NPP algorithms, and the paucity of detailed data on belowground NPP is evident. Indeed, it may be argued that the preferred algorithms for estimating NPP may be different for aboveground and belowground, taking into account the relative abundance of raw data and the likely standard error associated with individual monthly determinations of aboveground or belowground biomass. For example, Sims \& Singh (1978) reported that root productivity was most reliably estimated by summing positive increments in total root matter by depth - a variation on Method 4 . We also note that interannual variation in NPP may be significant (Fig. 3), although our statistical tests showed no interactions with year of measurement. We hope that the NPP ranges presented in Table 6 will prove useful to NPP modelers and others. For example, the relationships between NPP and climate variables are explored and discussed by Scurlock \& Olson (2001).

Although they are not the main thrust of the present analysis, crude root/shoot ratios based upon live biomass or standing crop appear to be an indicator of actual allocation of NPP. However, we would recommend caution in predicting belowground productivity from aboveground productivity since only modest errors in these ratios may result in wild extrapolations. Direct estimation of belowground NPP remains problematic and time consuming, and there is little substitute for hard field work (e.g. Long et al., 1989).

\section{Conclusions}

Our extensive analysis of grassland NPP estimates suggests that previous assumptions (such as the use of peak biomass as an indicator of NPP) may apply only within a certain range of a biome, e.g. temperate grassland steppes. This reinforces the earlier findings of Singh et al. (1975) that NPP estimates are strongly influenced by methodology, and that differences between NPP methods may be site-specific (Linthurst \& Reimold, 1978; Long et al., 1989). The additional data we have included here help to bring out some of the differences within the overall grassland biome.
To estimate and compare NPP across the widest range of sites without underestimating productivity, Methods 5 and 6 are recommended (depending upon exactly what data are available), since they sum-up positive growth increments, accounting for both live and dead matter. Perhaps surprisingly, peak live biomass (Method 1) nevertheless seems to be a fairly good indicator for the general ranking of study sites by productivity, across a wide range of climatic conditions and ecoregions. However, it is clearly an underestimate of the magnitude of NPP, and should not be taken at face value. The degree of underestimation may also vary significantly between subbiomes, and peak live biomass should not be used for comparisons between, say, temperate grasslands and tropical savannas (Long et al., 1989). However, peak live biomass may still be a reasonable benchmark indicator of the magnitude of productivity for study sites within a particular subbiome.

Although the present analysis was limited to known NPP estimation algorithms, we anticipate that future work on comparing NPP between different regions may involve the use of models such as CENTURY (Parton et al., 1993) or other biogeochemical models. Such models would generate intermediate components for computing NPP as a function of driving variables (e.g. the 'defac' decomposition factor in the model CENTURY), which may then be combined with actual measured field data to obtain a more 'complete' estimate of NPP.

Accounting for the dynamics of dead matter as well as live appears to be critically important in order to obtain representative estimates of NPP from different ecoregions within the grassland biome. Data on belowground dynamics are still badly lacking, despite our efforts to be as comprehensive as possible in our compilation, and new field studies cannot afford to neglect what goes on beneath the soil surface. We also strongly recommend that reports of grassland NPP from new field studies or syntheses should include discussion of the methodologies used for measurements and for NPP estimation. The international scientific community is slowly moving in the direction of common standards for field data collection, but thorough documentation of methods is essential in the mean time. There has been previously a disturbing tendency to trivialize the problems inherent in measuring and reporting NPP, which is evidently a critically important ecosystem variable.

\section{Acknowledgements}

This work was sponsored by the Terrestrial Ecology Program, Office of Earth Science, US National Aeronautics and Space Administration, under Interagency Agreement no. 2013-I096A1, under Lockheed Martin Energy Research Corporation contract DE-AC05-96OR22464 with the US Department of Energy. It 
was supported in part by an appointment (K. Johnson) to the ORNL research associates program, administered jointly by the Oak Ridge National Laboratory and the Oak Ridge Institute for Science and Education. The NPP data were compiled under the auspices of the Global Primary Production Data Initiative, an activity of the International Geosphere-Biosphere Programme Data and Information System. We thank Paul Hanson, Tony King and Mac Post of ORNL for comments on the manuscript.

\section{References}

Abrams MD, Knapp AK, Hulbert LC (1986) A ten year record of aboveground biomass in a Kansas tallgrass prairie: effects of fire and topographic position. American Journal of Botany, 73, 1509-1515.

Bailey RG (1989) Explanatory supplement to ecoregions map of the continents. Environmental Conservation, 16, 307-309.

Biondini ME, Lauenroth WK, Sala OE (1991) Correcting estimates of net primary production: are we overestimating plant production in rangelands? Journal of Range Management, 44, 194-198.

Buchmann N, Schulze ED (1999) Net $\mathrm{CO}_{2}$ and $\mathrm{H}_{2} \mathrm{O}$ fluxes of terrestrial ecosystems. Global Biogeochemical Cycles, 13, 751-760.

Christie EK (1978) Ecosystem processes in semi-arid grasslands. I. Primary production and water use of two communities possessing different photosynthetic pathways. Australian Journal of Agricultural Research, 29, 773-787.

Coupland RT (1973) Producers I Dynamics of Aboveground Standing Crop. Technical Report no. 27, Matador Project, Canadian Committeee for the International Biological Program, University of Saskatchewan, Saskatoon.

Cramer W, Kicklighter DW, Fischer A, Moore III B, Churkina G, Ruimy A, Schloss A (1999) Comparing global models of terrestrial net primary productivity (NPP): Overview and key results. Global Change Biology, 5 (Suppl. 1), 1-15.

Cramer W, Moore III B, Sahagian D (1996) Data needs for modelling global biospheric carbon fluxes - lessons from a comparison of models. IGBP Newsletter, 27, 13-15.

Daubenmire R (1972) Ecology of Hyparrhenia rufa in derived savanna in north-western Costa Rica. Journal of Applied Ecology, 9, 11-23.

Defosse GE, Bertiller MB, Ares JO (1990) Aboveground phytomass dynamics in a grassland steppe of Patagonia, Argentina. Journal of Range Management, 43, 157-160.

Garcia-Moya E, Montanez Castro P (1992) Saline grassland near Mexico City. In: Primary Productivity of Grass Ecosystems of the Tropics and Sub-Tropics (eds Long SP, Jones MB, Roberts MJ), pp. 70-99. Chapman \& Hall, London.

Gilmanov TG, Parton WJ, Ojima DS (1997) Testing the 'CENTURY' ecosystem level model on data sets from eight grassland sites in the former USSR representing a wide climatic/soil gradient. Ecological Modeling, 96, 191-210.

Hibbard K, Sahagian D, (eds) (1998) Net Primary Productivity Model Intercomparison Activity. IGBP/GAIM Report \#5, University of New Hampshire, Durham, NH, USA.

Jager HI, Hargrove WW, Brandt CC, King AW, Olson RJ, Scurlock JMO, Rose KA (2000) Constructive contrasts between modeled and measured climate responses over a regional scale. Ecosystems, 3, 396-411.

Kamnalrut A, Evenson JP (1992) Monsoon grassland in Thailand. In: Primary Productivity of Grass Ecosystems of the Tropics and Sub-Tropics (eds Long SP, Jones MB, Roberts MJ), pp. 100-126. Chapman \& Hall, London.

Kinyamario JI, Imbamba SK (1992) Savanna at Nairobi National Park, Nairobi. In: Primary Productivity of Grass Ecosystems of the Tropics and Sub-Tropics (eds Long SP, Jones MB, Roberts MJ), pp. 25-69. Chapman \& Hall, London.

Kucera DL, Dahlman RC, Koelling R (1967) Total net primary productivity and turnover on an energy basis for tallgrass prairie. Ecology, 48, 536-541.

Lauenroth WK, Sala OE (1992) Long-term forage production of North American shortgrass steppe. Ecological Applications, 2, 397-403.

Linthurst R, Reimold RJ (1978) An evaluation of methods for estimating the net primary production of estuarine angiosperms. Journal of Applied Ecology, 15, 919-932.

Long SP, Garcia Moya E, Imbamba SK et al. (1989) Primary productivity of natural grass ecosystems of the tropics: a reappraisal. Plant and Soil, 115, 155-166.

Long SP, Jones MB, Roberts MJ (eds) (1992) Primary Productivity of Grass Ecosystems of the Tropics and Sub-Tropics. Chapman \& Hall, London.

Menaut J-C, Cesar J (1979) Structure and primary productivity of Lamto savannas, Ivory Coast. Ecology, 60, 1197-1210.

Milner C, Hughes RE (1968) Methods for the Measurement of the Primary Production of Grassland. IBP Handbook no. 6. Blackwell, Oxford.

Olson RJ, Johnson KR, Zheng DL, Scurlock JMO (2001) Global and Regional Ecosystem Modeling: Databases of Model Drivers and Validation Measurements. ORNL Technical Memorandum TM-2001/196. Oak Ridge National Laboratory, Oak Ridge, Tennessee.

Parton WJ, Scurlock JMO, Ojima DS et al. (1993) Observations and modelling of biomass and soil organic matter dynamics for the grassland biome worldwide. Global Biogeochemical Cycles, 7, 785-809.

Roberts MJ, Long SP, Tieszen LL, Beadle CL (1993) Measurement of plant biomass and net primary production, pp. 1-21. In: Photosynthesis and Production in a Changing Environment: a Field and Laboratory Manual (eds Hall DO et al.). Chapman \& Hall, London.

San Jose JJ, Medina E (1976) Organic matter production in the Trachypogon savanna at Calabozo, Venezuela. Tropical Ecology, 17, 113-124.

Scholes RJ, Walker BH (1993) An African Savanna: Synthesis of the Nylsvley Study. Cambridge University Press, Cambridge, UK.

Scurlock JMO, Cramer W, Olson RJ, Parton WJ, Prince SD (1999) Terrestrial NPP: towards a consistent data set for global model evaluation. Ecological Applications, 9 (3), 913-919.

Scurlock JMO, Hall DO (1998) The global carbon sink: a grassland perspective. Global Change Biology, 4, 229-233.

Scurlock JMO, Olson RJ (2001) Terrestrial net primary productivity: a brief history and a new worldwide database (submitted to Environmental Reviews).

Sims PL, Singh JS (1978) The structure and function of ten western North American grasslands. III. Net primary production, 
turnover and efficiencies of energy capture and water use. Journal of Ecology, 66, 573-597.

Sims PL, Singh JS, Lauenroth WK (1978) The structure and function of ten western North American grasslands. I. Abiotic and vegetational characteristics. Journal of Ecology, 66, 251-285.

Singh JS, Joshi MC (1979) Tropical grasslands primary production. In: Grassland Ecosystems of the World (ed. Coupland RT). Cambridge University Press, pp. 197-218.

Singh JS, Lauenroth WK, Steinhorst RK (1975) Review and assessment of various techniques for estimating net aerial primary production in grasslands from harvest data. Botanical Review, 41, 181-232.

Singh JS, Yadava PS (1974) Seasonal variation in composition, plant biomass and net primary productivity of a tropical grassland at Kurukshetra, India. Ecological Monographs, 44, 351-376.

Snedecor GW, Cochran WG (1980) Statistical Methods, 7th edn. Iowa. State University Press, Ames, Iowa.

Togtohyn C, Ojima DS, Jargalsaihan L, Dodd J, Williams S (1996) Simulation studies of grazing in the Mongolian steppe. In:
Proceedings of the 5th Intl Rangelands Congress, Salt Lake City, USA, July 1995, Vol. I. (ed. West NE) Society for Range Management, Denver, pp. 561-562.

Wallentinus H-G (1973) Aboveground primary production of a Juncetum gerardi on a Baltic sea-shore meadow. Oikos, 24, 200-219.

Weigert RG, Evans FC (1964) Primary production and the disappearance of dead vegetation on an old field in south-eastern Michigan. Ecology, 45, 49-63.

Williamson P (1976) Aboveground primary production of chalk grassland allowing for leaf death. Journal of Ecology, 64, 1059-1075.

Xiao XM, Chen D, Peng YM, Cui XY, Ojima DS (1996b) Observation and modeling of plant biomass of meadow steppe in Tumugi, Xingan league, Inner Mongolia, China. Vegetatio, 127, 191-201.

Xiao XM, Jiang S, Wang YF, Ojima DS, Bonham CD (1996a) Temporal variation in aboveground biomass of Leymus chinense steppe from species to community levels in the Xilin River Basin, Inner Mongolia, China. Vegetatio, 123, 1-12. 